\title{
Long-term chronic stress exposure induces PCO phenotype in rat
}

\author{
S Divyashree and $\mathrm{H} \mathrm{N}$ Yajurvedi \\ Department of Zoology, University of Mysore, Mysuru, Karnataka, India \\ Correspondence should be addressed to H N Yajurvedi; Email: hnyajurvedi@rediffmail.com
}

\begin{abstract}
Thus far the effects of chronic stress on the ovary were studied for shorter durations. However, responses of the ovary may vary with durations of exposure to stress. Hence, we investigated the responses of the ovary following exposure to different durations of chronic stress. Exposure of rats to restraint $(1 \mathrm{~h})$ and after a gap of $4 \mathrm{~h}$ to forced swimming $(15 \mathrm{~min})$ daily for 4 or 8 weeks resulted in

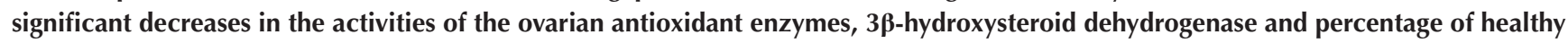
granulosa cells with concomitant increases in the number of atretic follicles, the percentage of apoptotic granulosa cells and ovarian malondialdehyde concentration. However, the response of the ovary to similar stress regime for 12 weeks was paradoxical as there

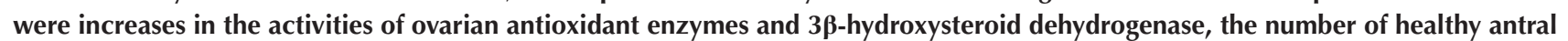
follicles, and decreases in ovarian malondialdehyde concentration and percentage of apoptotic granulosa cells. These changes were accompanied by hyperglycaemia and an increase in the serum levels of insulin, testosterone and oestradiol. In addition the cystic follicles were found in the ovaries of these rats. However, the number of oestrous cycles and active corpora lutea showed significant decrease in all the durations of stress exposure. The results demonstrate a differential response of ovary to short- and long-term exposure to chronic stress.

Reproduction (2016) 152 765-774
\end{abstract}

\section{Introduction}

The ovarian functions are influenced by several factors viz., light (Campbell \& Schwartz 1980), temperature (Roth et al. 2000, Saraswathi et al. 2010), radiation (Said et al. 2012), endocrine-disrupting chemicals (Patel et al. 2015), etc. In recent years, stress has emerged as one of the major factors interfering with female reproduction. Stress activates hypothalamus-pituitaryadrenal (HPA) axis (Chrousos et al. 1998). The activated HPA axis suppress the hypothalamus-pituitary-ovarian (HPO) axis (Whirledge \& Cidlowski 2010). Several studies have shown altered ovarian functions due to stress. For instance, stress-induced impairment in the follicular development (Roth et al. 2000, Ozawa et al. 2005, Bhat \& Yajurvedi 2011, Wu et al. 2011) and the developmental potential of oocytes (Zhang et al. 2011, Lian et al. 2013, Gao et al. 2016); blockage of ovulation (Daley et al. 1999); reduction in steroidogenesis (Whirledge \& Cidlowski 2010) and irregular oestrus cyclicity (Saraswathi et al. 2010) have been reported. Stress also results in oxidative damage due to increased production of free radicals (Spiers et al. 2015). Several studies have shown the role of reactive oxygen species (ROS) in the folliculogenesis, oocyte maturation and steroidogenesis (Agarwal et al. 2005, Gupta et al. 2008, Ruder et al. 2009). However an increase in ROS content in the follicular fluid environment results in early ovarian senescence (Gupta et al. 2008). Although a number of studies have shown chemical oxidants (Devine et al. 2012) and pathology-induced oxidative damage in the ovary (Agarwal et al. 2005), thus far there are only a couple of studies that demonstrate the stressinduced oxidative damage in the ovary (Saraswathi et al. 2012, Lian et al. 2013). In addition, whether the ovarian stress response, including antioxidant defence, differs according to duration of stress exposure is not known. It is possible that the stress effects on ovarian follicular development and antioxidant defence might be more severe with an increase in exposure period, or might remain in the same state, or the ovary may cease to respond due to habituation. Hence, this study tests the hypothesis that ovarian stress response with reference to antioxidant defence, follicular development and steroidogenic activity varies with durations of exposure.

\section{Materials and methods \\ Animals and experimental design}

Adult female Wistar rats in the weight range of 170-190g and exhibiting regular estrous cycles were obtained from the central animal house, University of Mysore, Mysuru. The rats were provided food and water ad libitum and maintained 
under 12-h light/12-h darkness photoperiod. This experiment was approved by the Institutional Animal Ethical Committee of University of Mysore and followed the guidelines of the committee for treatments and maintenance of animals. Three experiments were conducted and in each experiment, rats were divided into 2 groups viz., control and stress groups. Control rats were maintained without any disturbance, whereas each rat in stress group was exposed to two stressors according to the procedure of Grissom et al. (2008): restraint $(1 \mathrm{~h})$ in an open-ended cylindrical glass restrainer measuring $6.7 \mathrm{~cm}$ in diameter and $22.3 \mathrm{~cm}$ in length and then after a gap of $4 \mathrm{~h}$ to forced swimming (15 min) in a chromatographic jar of $45.72 \mathrm{~cm}$ height and $22.23 \mathrm{~cm}$ outer diameter, filled with $2 / 3 \mathrm{rd}$ of water at room temperature $\left(27 \pm 2^{\circ} \mathrm{C}\right)$. The rats were exposed to this stress regime every day for 4,8 and 12 weeks in experiments 1,2 and 3 respectively. In each experiment, stage of the estrous cycle of each rat was recorded every day by the vaginal smear method (Cooper et al. 1993). The average number of estrous cycles per 4 weeks per group was determined at the end of each experiment. After completion of each experiment rats in control and stress groups were autopsied. At each autopsy, blood sample, the ovaries and the adrenal glands were collected and processed for different analyses as described in the following section.

\section{Fasting blood glucose concentration}

Fasting blood glucose concentration was estimated in all the rats at weekly intervals throughout the experimentation by collecting blood samples from tail vein and using GOD-POD kit (Barham \& Trinder 1972).

\section{Biochemical analyses}

The ovary was homogenised in O.32M sucrose solution, centrifuged and the supernatant was used for assays to quantify the activities of different enzymes viz., 3 $\beta$-hydroxysteroid dehydrogenase $(3 \beta-\mathrm{HSDH})$ (Shivanandappa \& Venkatesh 1997), superoxide dismutase (SOD) (Marklund \& Marklund 1974), catalase (CAT) (Aebi 1984), glutathione S-transferase (GST) (Habig et al. 1974) and glutathione peroxidase (GPx) (Tappel 1978). The ferric reducing antioxidant power (FRAP) (Benzie \& Strain 1996) and malondialdehyde concentration (MDA) (Ohkawa et al. 1979) were also determined in the ovary.

\section{Hormone assays}

Serum concentrations of estradiol, testosterone, insulin (Calbiotech, Spring Valley, CA, USA) and corticosterone (Demeditec diagnostics $\mathrm{GmbH}$, Germany) were estimated using ELISA kits and procedures provided by the respective manufacturer.

\section{Histological study}

Serial paraffin sections $(5 \mu \mathrm{m})$ of the ovary were cut and stained with haematoxylin and eosin. The antral follicles were identified according to the description of Pedersen and Peters (1968). Each section of the ovary was focused and the number of antral follicles of 380-740 $\mu \mathrm{m}$ size showing full-size oocytes was recorded. Care was taken to avoid counting the same follicle more than once and healthy and atretic follicles were separately counted. The aggregate of follicles in all the sections was expressed as the number of antral follicles/ovary/ rat. The criteria for identification of atretic follicles were as per the description of Greenwald and Roy (1994).

The number of active corpora lutea was counted focussing each section of the ovary under $40 \times$, and avoiding counting the same corpora lutea more than once. The active (newly formed) corpora lutea were identified based on the presence of active luteal cells and angiogenesis between them, whereas regressing (previously formed) corpora lutea showed vacuolated and apoptotic cells with fibrosis (Yoshida et al. 2009).

\section{Apoptosis}

Granulosa cells were isolated from the ovary (Campbell 1979) and analysed for apoptosis by using acridine orange (AO) and ethidium bromide (EB) stains $(1: 10.01 \%$ AO:EB) (Kasibhatla et al. 2006). The apoptotic cells emitted yellow or orange fluorescence whereas healthy cells emitted green fluorescence. One hundred randomly selected cells per ovary were scanned and the number of apoptotic and healthy cells was recorded and percentage of apoptotic cells was computed.

\section{DNA ladder assay}

The DNA was extracted from the ovary following the method of Compton (1992). The DNA samples were subjected to agarose gel (2\%) electrophoresis and changes were documented using gel doc.

\section{Statistical analyses}

The mean value of each parameter was computed considering data on 5 rats/group. The mean values of control and stress group were compared using Student's $t$-test and judged significant if $P<0.05$. Since rats in $1 \mathrm{st}, 2 \mathrm{nd}$ and $3 \mathrm{rd}$ experiments belonged to different age groups, Student's $t$-test was preferred to test the significance between control and stress groups in each experiment, rather application of ANOVA considering all the groups in 3 experiments.

\section{Results}

\section{Stress markers}

Weight of the body and the adrenal gland

There was a significant increase in body weight of controls in each experiment as shown by percent increase in body weight compared with initial body weight, whereas that of rats in stress groups in all the exposure periods was significantly lower than the respective controls (Table 1). The weight of the adrenal gland was significantly increased in rats of stress group in each duration compared with the respective controls (Table 1 ). 


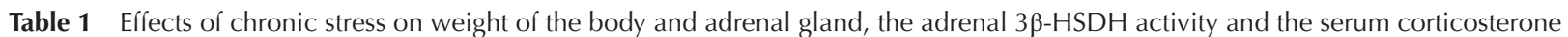
concentration of rats.

\begin{tabular}{|c|c|c|c|c|}
\hline Groups & $\begin{array}{l}\% \text { change in body weight } \\
\text { compared to initial body } \\
\text { weight }(n=8)\end{array}$ & $\begin{array}{l}\text { Relative weight of the } \\
\text { adrenal gland (mg/100 g } \\
\text { body weight) }(n=8)\end{array}$ & 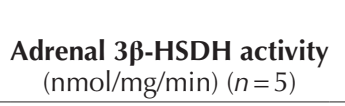 & $\begin{array}{c}\text { Serum concentration of } \\
\text { corticosterone }(\mathrm{ng} / \mathrm{mL})(n=5)\end{array}$ \\
\hline \multicolumn{5}{|c|}{ 4-week exposure } \\
\hline Control & $14.35 \pm 1.22$ & $26.88 \pm 1.11$ & $0.48 \pm 0.02$ & $127.50 \pm 19.20$ \\
\hline Stress & $6.84 \pm 1.62$ & $31.60 \pm 0.68$ & $0.73 \pm 0.08$ & $457.50 \pm 12.50$ \\
\hline$P$ & $<0.003$ & $<0.05$ & $<0.05$ & $<0.001$ \\
\hline \multicolumn{5}{|c|}{ 8-week exposure } \\
\hline Control & $6.67 \pm 1.81$ & $28.38 \pm 1.03$ & $0.37 \pm 0.01$ & $210.00 \pm 26.22$ \\
\hline Stress & $-3.19 \pm 2.04$ & $37.71 \pm 0.81$ & $0.48 \pm 0.01$ & $456.25 \pm 3.75$ \\
\hline$P$ & $<0.05$ & $<0.001$ & $<0.001$ & $<0.001$ \\
\hline \multicolumn{5}{|c|}{ 12-week exposure } \\
\hline Control & $5.69 \pm 0.24$ & $27.75 \pm 0.84$ & $0.23 \pm 0.01$ & $162.50 \pm 17.02$ \\
\hline Stress & $1.58 \pm 0.11$ & $37.00 \pm 1.09$ & $0.34 \pm 0.01$ & $405.00 \pm 31.75$ \\
\hline$P$ & $<0.001$ & $<0.001$ & $<0.001$ & $<0.003$ \\
\hline
\end{tabular}

All the values are mean \pm S.E.

Mean values of control and stress groups were compared using Student's $t$-test and judged significant if $P<0.05$.

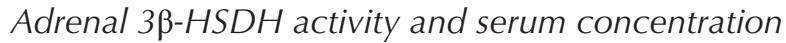 of corticosterone}

The activity of the adrenal $3 \beta-\mathrm{HSDH}$ and the serum concentration of corticosterone were significantly increased in rats exposed to stressors in each duration compared with the respective controls (Table 1).

\section{Fasting blood glucose concentration}

Fasting blood glucose concentration estimated at weekly intervals showed a significant increase from 2 nd week through 12th week (except 6th week) in stress group rats compared with controls in 12-week exposure experiment (Fig. 1). The fasting blood glucose concentrations of rats in 1 st and 2 nd experiments wherein the rats were exposed to stress for 4 and 8 weeks, respectively, resembled those of 4- and 8-week exposure in the third experiment.

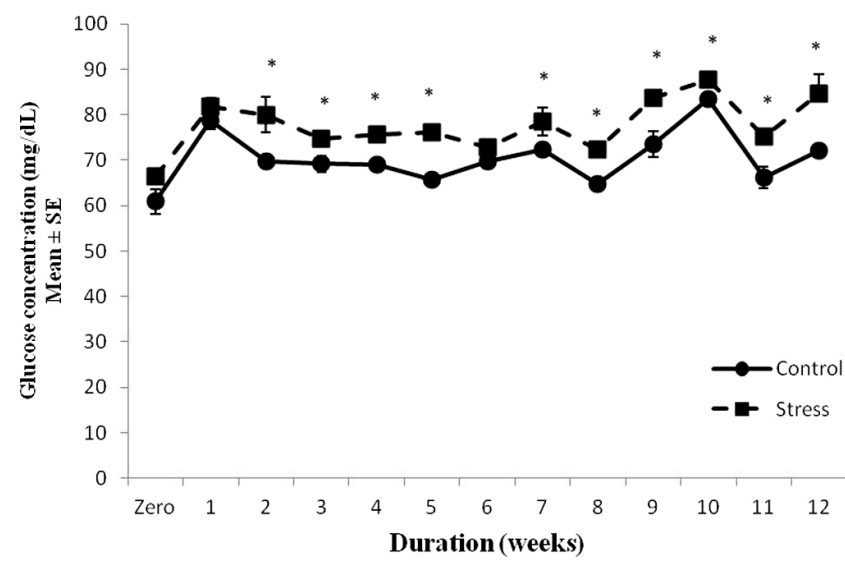

Figure 1 Fasting blood glucose concentrations in control and rats exposed to stress for 12 weeks. Note the higher levels of glucose in stressed rats compared with controls. The data on blood glucose levels of rats exposed to stress for 4 and 8 weeks (i.e., 1 st and 2 nd experiment) are not included, as these did not significantly differ from the values following 4- and 8-week exposure in 12-week exposure experiment. *significantly $(P<0.05)$ different compared with controls as judged by Student's $t$-test.
Hence, data of the 1 st and 2nd experiments were not presented to avoid repetition.

\section{Estrous cyclicity}

The average number of estrous cycles/4 weeks was significantly lower in stress group rats of all the exposure periods compared with the respective controls (Table 2).

\section{Hormone profile}

The serum estradiol concentration did not differ in rats after 4-week stress exposure compared with controls, whereas it was significantly increased after 8 or 12 weeks of stress exposure compared with the respective controls (Table 2). The serum levels of testosterone did not differ after 4- or 8-week exposure to stressors, whereas it was significantly increased after 12-week exposure compared with the respective controls. The serum insulin concentration was significantly decreased after 4-week exposure to stressors, whereas it was significantly increased after 8- or 12-week exposure compared with controls (Table 2).

\section{Ovarian changes}

Weight of the ovary

The weight of the ovary was significantly lower in rats exposed to stressors for 4 and 8 weeks, whereas it was significantly higher in rats exposed to stress for 12 weeks compared with the respective controls (Table 2).

\section{$3 \beta-H S D H$ activity}

The ovarian $3 \beta-\mathrm{HSDH}$ activity was significantly decreased in 4- and 8-week stressed rats, whereas it was significantly increased after 12 weeks of stress exposure compared with the respective controls (Table 2). 
Table 2 Effects of chronic stress on oestrous cyclicity, ovarian weight and serum hormone concentrations in rats.

\begin{tabular}{|c|c|c|c|c|c|c|}
\hline Groups & $\begin{array}{l}\text { Relative weight of } \\
\text { ovary (mg/100g } \\
\text { body weight) }(n=8)\end{array}$ & $\begin{array}{c}\text { Ovarian } 3 \boldsymbol{\beta}-\mathrm{HSDH} \\
\text { activity } \\
(\mathrm{nmol} / \mathrm{mg} / \mathrm{min})(n=5)\end{array}$ & $\begin{array}{c}\text { Average number of } \\
\text { oestrous cycles/month } \\
(n=8)\end{array}$ & $\begin{array}{c}\text { Serum oestrogen } \\
\text { concentration } \\
(\mathrm{pg} / \mathrm{mL})(n=5)\end{array}$ & $\begin{array}{l}\text { Serum testosterone } \\
\text { concentration } \\
(\mathrm{ng} / \mathrm{mL})(n=5)\end{array}$ & $\begin{array}{c}\text { Serum insulin } \\
\text { concentration } \\
(\mu \mathrm{IU} / \mathrm{mL})(n=5)\end{array}$ \\
\hline \multicolumn{7}{|c|}{ 4-week exposure } \\
\hline Control & $43.50 \pm 1.04$ & $0.62 \pm 0.08$ & $6.14 \pm 0.26$ & $17.50 \pm 3.23$ & $0.75 \pm 0.010$ & $13.63 \pm 1.07$ \\
\hline Stress & $33.80 \pm 2.33$ & $0.34 \pm 0.03$ & $4.00 \pm 0.31$ & $13.33 \pm 1.67$ & $0.58 \pm 0.08$ & $3.17 \pm 1.48$ \\
\hline$P$ & $<0.003$ & $<0.05$ & $<0.001$ & NS & NS & $<0 . \overline{0} 03$ \\
\hline \multicolumn{7}{|c|}{ 8-week exposure } \\
\hline Control & $50.25 \pm 2.01$ & $0.39 \pm 0.03$ & $5.64 \pm 0.32$ & $19.17 \pm 5.69$ & $1.25 \pm 0.08$ & $8.60 \pm 1.17$ \\
\hline Stress & $41.00 \pm 0.89$ & $0.26 \pm 0.01$ & $4.42 \pm 0.15$ & $61.67 \pm 3.33$ & $1.00 \pm 0.14$ & $13.33 \pm 0.60$ \\
\hline$P$ & $<0.05$ & $<0.05$ & $<0.05$ & $<0.001$ & NS & $<0.05$ \\
\hline \multicolumn{7}{|c|}{ 12-week exposure } \\
\hline Control & $38.17 \pm 3.52$ & $0.19 \pm 0.01$ & $5.55 \pm 0.33$ & $23.33 \pm 2.79$ & $0.83 \pm 0.15$ & $6.40 \pm 1.04$ \\
\hline Stress & $51.00 \pm 2.65$ & $0.30 \pm 0.00$ & $4.13 \pm 0.20$ & $38.33 \pm 1.67$ & $1.56 \pm 0.12$ & $25.25 \pm 4.71$ \\
\hline$P$ & $<0.05$ & $<0.001$ & $<0.05$ & $<0.003$ & $<0.05$ & $<0.05$ \\
\hline
\end{tabular}

All the values are mean \pm S.E.M.

Mean values of control and stress groups were compared using Student's $t$-test and judged significant if $P<0.05$.

\section{Counts of antral follicles and corpora lutea}

The mean number of healthy antral follicles was significantly lower and higher in rats exposed to stressors for 4 and 12 weeks respectively compared with controls, whereas it did not differ significantly from controls following 8-week stress exposure (Table 3). However, the number of atretic antral follicles showed significant increase in stress-exposed rats of each duration compared with controls (Table 3).

The mean number of active corpora lutea was significantly lower in stress group rats in all the durations compared with the respective controls (Table 3). In addition, the ovaries of rats exposed to stress for 12 weeks were conspicuous by the presence of cystic follicles in a range of 2-5/ovary with a mean of $3.4 \pm 0.51$. The cystic follicles contained fluid-filled cavity surrounded by granulosa and theca layers and the thickness of the thecal layer was more than that of antral follicles of controls (Fig. 2). However, cystic follicles were not found in the ovaries of rats exposed to stress for 4 or 8 weeks.

\section{Apoptosis of granulosa cells}

The percentage of healthy granulosa cells was significantly decreased in rats exposed to stressors for 4 and 8 weeks and increased significantly after 12-week exposure to stressors. There was a significant increase in the percentage of apoptotic granulosa cells after 4 (Fig. 3) and 8 weeks of stress regime, but it was decreased after 12-week exposure to stressors compared with the respective controls (Table 3 ).

\section{DNA ladder assay}

The breaks in the DNA of the ovary as shown by the formation of the ladder was observed in rats exposed to stress for 8 weeks, whereas after 4 or 12 weeks of exposure to stress DNA of the ovary did not show such breaks (Fig. 4).

\section{Activity of antioxidant enzymes}

The activities of antioxidant enzymes SOD, GST and GPx in the ovary were significantly decreased in rats

Table 3 Effects of chronic stress on follicle development and apoptosis of the granulosa cells in rat.

\begin{tabular}{|c|c|c|c|c|c|}
\hline \multirow[b]{2}{*}{ Groups } & \multicolumn{2}{|c|}{ Mean number of antral follicle \pm S.E. } & \multirow{2}{*}{$\begin{array}{c}\text { Mean number of active } \\
\text { corpora lutea } \pm \text { S.E. }(n=5)\end{array}$} & \multicolumn{2}{|c|}{ Percentage of granulosa cells } \\
\hline & Healthy $(n=5)$ & Atretic $(n=5)$ & & Healthy $(n=5)$ & Apoptotic $(n=5)$ \\
\hline \multicolumn{6}{|l|}{4 weeks } \\
\hline Control & $21.25 \pm 0.48$ & $11.25 \pm 0.63$ & $7.25 \pm 0.48$ & $30.32 \pm 3.58$ & $69.33 \pm 1.32$ \\
\hline Stress & $16.00 \pm 0.41$ & $15.25 \pm 0.85$ & $2.25 \pm 0.63$ & $18.64 \pm 2.24$ & $80.79 \pm 4.83$ \\
\hline$P$ & $<0.001$ & $<0.05$ & $<0.003$ & $<0.05$ & $<0.05$ \\
\hline \multicolumn{6}{|l|}{8 weeks } \\
\hline Control & $21.50 \pm 0.96$ & $8.25 \pm 0.95$ & $9.00 \pm 0.71$ & $16.88 \pm 0.87$ & $82.54 \pm 0.66$ \\
\hline Stress & $24.00 \pm 1.22$ & $16.50 \pm 0.65$ & $3.25 \pm 0.48$ & $12.95 \pm 0.33$ & $87.83 \pm 0.49$ \\
\hline$P$ & $(\overline{N S})$ & $<0.001$ & $<0.003$ & $<0.05$ & $<0.05$ \\
\hline \multicolumn{6}{|l|}{12 weeks } \\
\hline Control & $10.67 \pm 1.20$ & $5.75 \pm 1.25$ & $6.25 \pm 0.63$ & $11.30 \pm 2.03$ & $88.83 \pm 2.01$ \\
\hline Stress & $17.75 \pm 1.31$ & $12.00 \pm 1.08$ & $1.25 \pm 0.25$ & $17.43 \pm 0.69$ & $82.41 \pm 1.09$ \\
\hline$P$ & $<0.05$ & $<0.05$ & $<0.001$ & $<0.05$ & $<0.05$ \\
\hline
\end{tabular}

All the values are mean \pm S.E.M.

Mean values of control and stress groups were compared using Student's $t$-test and judged significant if $P<0.05$. 
A

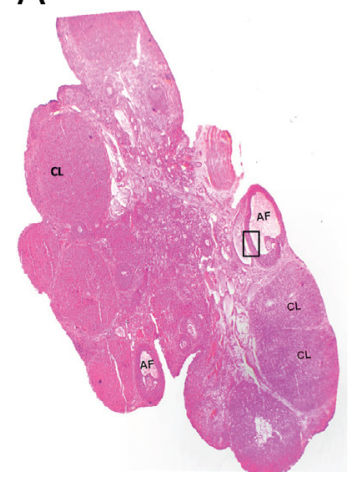

B

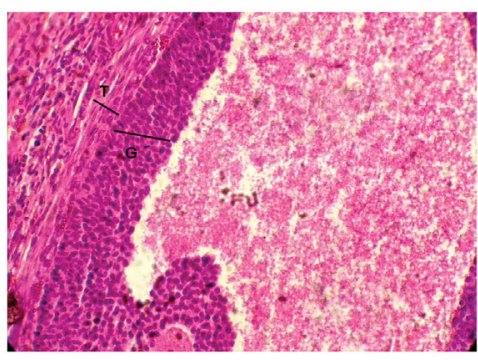

C

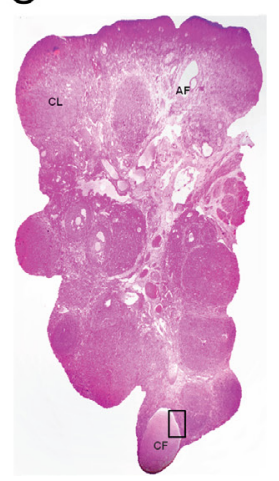

D

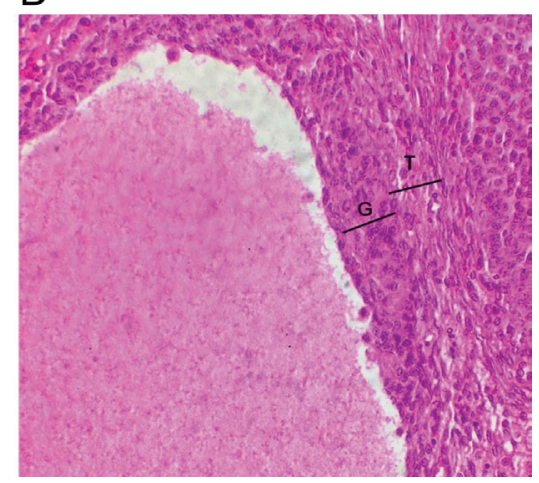

Figure 2 (A-D) Photomicrographs of the cross sections of the ovary of control (A \& B) and rats exposed to stress for 12 weeks (C \& D). B and D are the enlarged views of a portion of follicular wall of the ovaries in A and B respectively. Note the presence of cystic follicle (CF, C) and an increase in the thickness of theca layer in cystic follicle (D) in stressed rat compared with that of the antral follicle of control rat (B) (H\&E, A \& B, 40x; C \& D, 200×). AF, antral follicle; CL, corpus luteum; G, granulosa layer; T, theca layer.
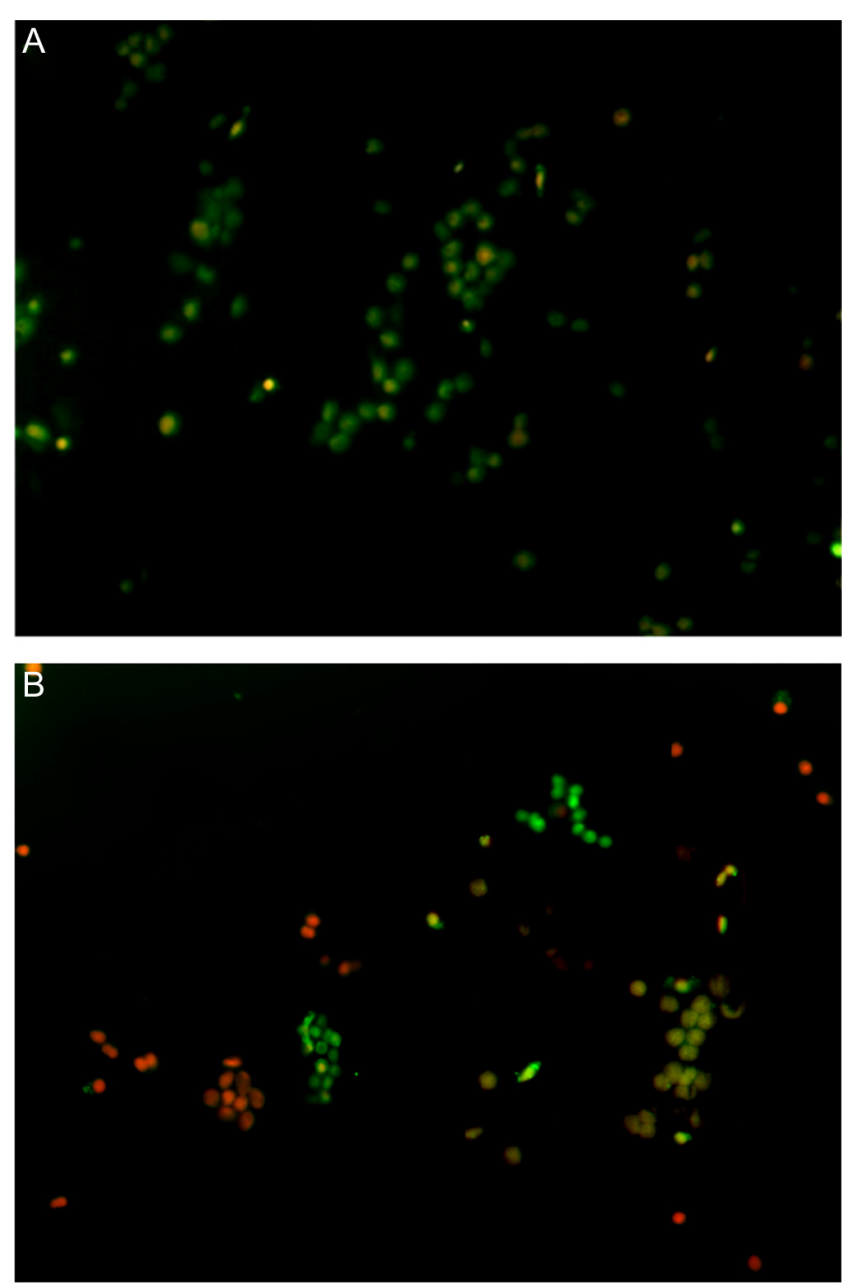

Figure 3 ( $A$ and $B$ ) Photomicrographs of the ovarian granulosa cells stained with acridine orange and ethidium bromide in control (A) and stress group (B) rats after 4-week stress. Green colour represents the healthy, and yellow or orange colour represents the apoptotic cells. Note the presence of more number of healthy cells in control group whereas more number of apoptotic cells in stressed rats. exposed to stressors for 4 or 8 weeks, whereas there was a significant increase in activities of these enzymes following 12-week exposure to stressors, compared with the respective controls (Table 4). However, the activity of CAT and FRAP were significantly decreased in all the durations of stress exposure (Table 4).

\section{Malondialdehyde concentration}

The malondialdehyde concentration in the ovaries of the rats exposed to stressors for 4 or 8 weeks showed a significantly higher concentration whereas that in the ovaries of rats exposed to stress for 12 weeks was significantly lower compared with the respective controls (Table 5).

\section{Discussion}

The immediate response of mammals to stress is an activation of the HPA axis (Chrousos et al. 1998). In this study, an increase in the adrenocortical activity as shown by an increase in the relative weight and

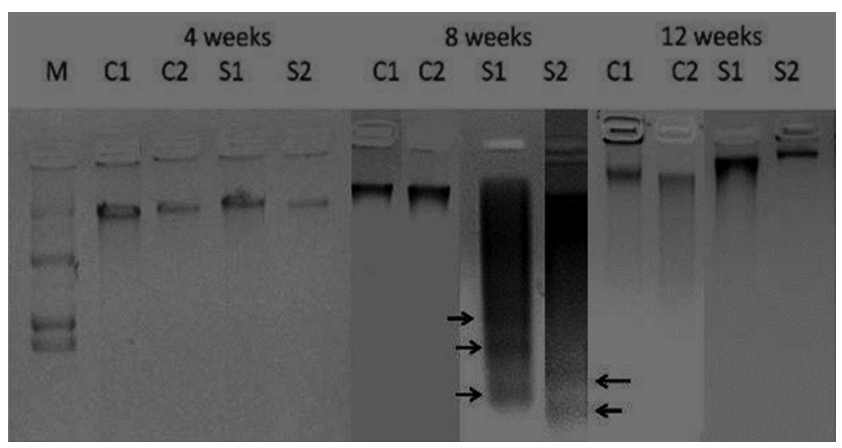

Figure 4 Photomicrographs of gel electrophoretic profile of DNA from the ovaries of rats exposed to stress for 4, 8 and 12 weeks and control rats. Note the presence of DNA breaks only in rats exposed to stress for 8 weeks whereas no such breaks in rats exposed to stress for 4 or 12 weeks. C, control lane; M, marker lane; S, stress lane. 
Table 4 Effects of chronic stress on the activities of antioxidant enzymes and ferrous reducing antioxidant power (FRAP) of ovary in rat.

\begin{tabular}{|c|c|c|c|c|c|}
\hline Groups & $\begin{array}{c}\text { SOD (U/mg protein }) \\
(n=5)\end{array}$ & 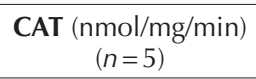 & 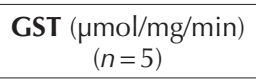 & $\underset{(n=5)}{\mathbf{G P x}} \underset{(\mu \mathrm{mol} / \mathrm{mg} / \mathrm{min})}{ }$ & $\begin{array}{c}\text { FRAP } \underset{(n=5)}{\left(\mu \mathrm{mol} / \mathrm{L} \mathrm{FeSO}_{4}\right)} \\
\text { (n) }\end{array}$ \\
\hline \multicolumn{6}{|c|}{ 4-week exposure } \\
\hline Control & $0.090 \pm 0.00$ & $0.0017 \pm 0.00$ & $698.61 \pm 40.93$ & $0.176 \pm 0.04$ & $546.47 \pm 104.11$ \\
\hline Stress & $0.04 \pm 0.00$ & $0.0005 \pm 0.00$ & $267.07 \pm 53.37$ & $0.079 \pm 0.01$ & $129.22 \pm 14.81$ \\
\hline$P$ & $<0.001$ & $<0.003$ & $<0.001$ & $<0.05$ & $<0.05$ \\
\hline \multicolumn{6}{|c|}{ 8-week exposure } \\
\hline Control & $0.126 \pm 0.01$ & $0.0025 \pm 0.00$ & $333.60 \pm 3.69$ & $0.064 \pm 0.00$ & $495.68 \pm 39.91$ \\
\hline Stress & $0.078 \pm 0.01$ & $0.0014 \pm 0.00$ & $183.04 \pm 6.30$ & $0.017 \pm 0.00$ & $161.08 \pm 12.81$ \\
\hline$P$ & $<0.003$ & $<0 . \overline{05}$ & $<0.001$ & $<0.001$ & $<0.001$ \\
\hline \multicolumn{6}{|c|}{ 12-week exposure } \\
\hline Control & $0.075 \pm 0.01$ & $0.0023 \pm 0.00$ & $252.97 \pm 16.25$ & $0.011 \pm 0.00$ & $882.59 \pm 34.66$ \\
\hline Stress & $0.114 \pm 0.01$ & $0.0014 \pm 0.00$ & $452.60 \pm 9.93$ & $0.064 \pm 0.00$ & $510.15 \pm 133.14$ \\
\hline$P$ & $<0.05$ & $<0.05$ & $<0.001$ & $<0.001$ & $<0.05$ \\
\hline
\end{tabular}

All the values are mean \pm S.E.M.

Mean values of control and stress groups were compared using Student's $t$-test and judged significant if $P<0.05$.

$3 \beta-\mathrm{HSDH}$ activity of the adrenal gland and serum corticosterone concentration in rats subjected to restraint and forced swimming in all the experiments reveals that the rats were under stress. It is further supported by a decrease in percentage gain in body weight of rats in all the durations of exposure, because loss of body weight is associated with stress (Jeong et al. 2013). Since stress induces hyperglycaemia (Nirupama et al. 2010), an increase in fasting blood glucose concentration observed in stressed rats throughout the experiment from 2 nd week of stress exposure in this study also suggests that rats were under stress. It is remarkable that even after 12 weeks of everyday exposure to stressors, the rats showed an adrenal stress response, thereby indicating that rats were not habituated to stress regime. Concomitant with activation of the adrenocortical activity in stressed rats, ovarian functions viz., follicle development, steroidogenesis and antioxidant status were altered. Hence, these changes were ovarian stress responses.

Several earlier studies reported stress-induced alterations in ovarian functions. For instance, irregular estrous cyclicity in rats (Saraswathi et al. 2010,

Table 5 Durational effects of chronic stress on the concentration of malondialdehyde (MDA) in the ovary of rat.

\begin{tabular}{lc}
\hline Groups & MDA concentration $(\mathrm{nmol} / \mathrm{mg}$ protein) $(n=5)$ \\
\hline 4-week exposure & \\
Control & $328.10 \pm 17.19$ \\
Stress & $876.45 \pm 62.41$ \\
$P$ & $<0.001$ \\
8-week exposure & $194.70 \pm 10.92$ \\
Control & $372.99 \pm 58.79$ \\
Stress & $<0.05$ \\
$P$ & $285.66 \pm 21.06$ \\
12-week exposure & $177.69 \pm 4.76$ \\
Control & $<0.003$ \\
Stress & \\
$P$ &
\end{tabular}

All the values are mean \pm S.E.M.

Mean values of control and stress groups were compared using

Student's $t$-test and judged significant if $P<0.05$.
Mourlon et al. 2011) and altered ovarian follicular development in cows (Bos taurus) (Roth et al. 2000), rats (Dorfman et al. 2003, Bhat \& Yajurvedi 2011, Barra et al. 2014), goat (Capra hircus) (Ozawa et al. 2005) and mice (Wu et al. 2011) have been reported. Further, stress-induced impairment in developmental potential of oocyte (Zhang et al. 2011, Lian et al. 2013, Gao et al. 2016) and reduction in ovulatory rate (Zhang et al. 2011) have been observed in mice. Similarly, changes in secretions of reproductive hormones are also observed due to stress (Roth et al. 2000). The results of this study, i.e., irregular estrous cyclicity, reduction in the number of antral follicles and active corpora lutea as well as a decrease in ovarian $3 \beta-\mathrm{HSDH}$ activity and antioxidant potential after 4- or 8-weeks exposure to stress indicate impaired ovarian functions and are in agreement with earlier studies. However, the maximum duration of stress exposure in the above studies was 30 days, whereas this study demonstrates that the ovary continues to show stress response beyond 30 days. Further the study reveals for the first time a paradoxical response of the ovary after 12-week exposure compared with 4- or 8-week exposure, as there was an increase in the number of antral follicles, serum oestrogen and testosterone levels coupled with an increase in antioxidant status of the ovary. On the contrary, Paredes et al. (1998) reported formation of precystic follicles following 3-week coldrestraint stress exposure, whereas the ovary resembled controls excepting a decrease in the total number of healthy pre-antral and antral follicles after 11-week stress exposure. The differences between the study by Paredes et al. (1998) and this study will be further discussed.

Exposure to stressors activates the HPA axis resulting in increased secretion of corticotrophin-releasing hormone and adrenocorticotropic hormone leading to the activation of the adrenal cortex and results in an increase in secretion of glucocorticoids (Daley et al. 1999, Levy \& Tasker 2012). Corticotrophin-releasing hormone suppresses GnRH secretion (Kyrou \& Tsigos 2008) whereas glucocorticoids inhibit gonadotrophin 
secretion (Breen et al. 2004, Levy \& Tasker 2012) and also directly interfere with ovarian functions by triggering apoptosis of ovarian granulosa and cumulus cells (Whirledge \& Cidlowski 2010, Yuan et al. 2016). Since gonadotrophins are key regulating hormones, impairment in their secretion/action results in altered ovarian activities under stressful conditions. In this study, there was an activation of the adrenal cortex coupled with higher levels of corticosterone in all the durations of stress exposure. Hence, alterations in the ovarian activity might be due to suppressive actions of HPA axis hormones.

In addition to stress-induced hormonal imbalance, compromise in antioxidant status of the ovary might also adversely affect ovarian activities because stress (Nayanatara et al. 2005) and high levels of glucocorticoids (Spiers et al. 2015) cause an increase in the generation of ROS due to accelerated metabolic reactions (Liu \& Mori 1999) resulting in oxidative damage in tissues. In addition, restraint-induced oxidative stress impaired developmental potential of oocytes, whereas administration of antioxidants overcame this detrimental effect (Lian et al. 2013). Hence, this study determined whether stress-induced hormonal imbalance was accompanied by oxidative stress in the ovary. Indeed, ovaries of rats after 4 or 8 weeks of stress exposure showed an increase in the concentration of MDA concomitant with a decrease in the activity levels of antioxidant enzymes (SOD, CAT, GST and GPx) and thereby indicated a state of oxidative stress. Increased concentration of MDA suggests high level of ROS (Mittal et al. 2014), which is known to induce granulosa cell apoptosis (Sinha et al. 2013). Hence an increase in atresia of antral follicles and apoptosis of granulosa cells determined by acridine orange and ethidium bromide staining in this study were due to damage caused by ROS. The fact that though oxidative stress was found after 4- as well as 8-week exposure, the DNA breaks in ovarian tissue was observed only after 8-week exposure, indicating the severity of stress effects on the DNA to increase with duration of exposure. However, despite longer duration of exposure, DNA breaks were not observed in rats exposed to stress for 12 weeks. In these rats the antioxidant potential of the ovary was higher than the controls as shown by an increase in the antioxidant enzyme activities and decrease in the MDA levels in the ovary. A decrease in the oxidative stress due to altered ovarian functions, discussed in the later section, may be the reason for the absence of DNA breaks in rats exposed to stress for 12 weeks.

Thus far studies have reported inhibitory effects of stress on ovarian functions (Whirledge \& Cidlowski 2010). However, this study demonstrates the paradoxical response of the ovary following exposure to longer duration (12 weeks), as shown by increases in the number of healthy follicles, steroidogenic activity and antioxidant potential in contrast to decrease in these parameters following 4- or 8-week stress exposure. The altered response of the ovary might be due to the prevalence of hyperandrogenism after 12-week exposure. The testosterone stimulates follicular growth (Murray et al. 1998, Sen et al. 2014); promotes theca and granulosa cell proliferation and inhibits apoptosis (Das et al. 2008); promotes gonadotrophin responsiveness and steroidogenesis in granulosa cells (Hillier 1994); augments follicle FSH receptor expression and growth (Weil et al. 1999, Sen et al. 2014) and induces IGF and IGF1 receptor expression in the ovary (Vendola et al. 1999). These actions put together increase the number of healthy follicles, which consequently results in increases in other parameters. The fact that hyperandrogenism after 12-week stress was accompanied by an increase in the number of follicles, whereas low levels of androgen following 4- or 8-week stress were accompanied by a decrease in the number of follicles, further supports hyperandrogenism-induced follicular excess. One of the features of the polycystic ovary (PCO) is hyperandrogenism (Gambineri et al. 2002). Indeed, in this study there was development of cystic follicles in the ovaries of rats exposed to stress for 12 weeks concomitant with an increase in serum testosterone levels. In addition, these rats also exhibited other characteristics of PCO phenotype viz., irregular oestrous cyclicity, hyperestrogenism, hyperinsulinaemia, follicular excess and follicular arrest. In addition androgen (Mancini et al. 2008) and oestrogen (Borras et al. 2010) are known to stimulate antioxidant system. In this study on rats exposed to stress for 12 weeks, there was an increase in antioxidant potential of ovary as shown by elevated activities of antioxidant enzymes and decrease in lipid peroxidation concomitant with higher serum levels of testosterone and estrogen. Thus the altered paradoxical response of the ovary after 12 weeks of stress was due to pathophysiological development i.e., polycystic ovarian condition.

Interestingly, Paredes et al. (1998) observed the formation of precystic follicles following 3-week stress due to cold-restraint exposure, but not after a similar stress regime for 11 weeks, though there was a decrease in the total number of healthy pre-antral and antral follicles in both the durations of exposure. However, in the present study, cysts were not observed in the ovary after 4- or 8-week stress exposure, whereas these were formed after 12 weeks of stress due to restraint and forced swimming. The difference in these two studies may due to the fact that hyperandrogenism, which causes cyst formation in the ovary, was found after 3 -week exposure but not after 11 weeks in the study by Paredes et al. (1998), whereas in this study it was found after 12-week exposure. Further, Paredes et al. (1998) suggested that a decrease in the total number of healthy pre-antral and antral follicles in their study was due to increased rate of follicular development caused by cold-restraint-induced sympathetic overstimulation 
of the ovarian activity. On the contrary, in the present study the number of healthy antral follicles was increased after 12-week exposure concomitant with hyperandrogenism. Thus, follicular excess was due to hyperandrogenism in this study in contrast to stressinduced increased rate of follicular development in that of Paredes et al. (1998).

Several factors viz., genetic and environmental (prenatal and postnatal) (de Melo et al. 2015), obesity (Gambineri et al. 2002) and stress (Paredes et al. 1998, Dorfman et al. 2003, Greiner et al. 2005, Saraswathi et al. 2012) are known to cause polycystic ovary phenotype. In earlier studies, it was shown that sympathetic activation induced by stress due to chronic cold exposure resulted in PCO phenotype (Paredes et al. 1998, Dorfman et al. 2003, Greiner et al. 2005) whereas involvement of HPA axis was yet to be demonstrated. This study is the first to demonstrate occurrence of PCO condition due to chronic stress-induced activation of the HPA axis in normally cycling non-obese rats. Moreover, this study also reveals the pathogenesis of the PCO condition as mentioned below.

Chronic stress is known to cause hyperglycaemia due to dysregulation of carbohydrate metabolism (Zardooz et al. 2006, Nirupama et al. 2010), which consequently leads to hyperinsulinaemia (Tomas et al. 2002). In this study, in rats a consistent hyperglycaemia was observed after 2-week stress exposure, which was accompanied by a decrease in serum insulin concentration following 4-week exposure and hyperinsulinaemia after 8- or 12 -week exposure. High concentration of corticosterone is known to increase insulin degrading enzyme (IDE) expression in the liver under stress (Zardooz et al. 2006). Since there was a consistent increase in the serum concentration of corticosterone in all the durations of exposure in this study, a decrease in the serum insulin levels after 4-week exposure may be due to activation of IDE. However, after longer duration of stress exposure, insulin resistance might have developed due to consistent hyperglycaemia resulting in hyperinsulinaemia despite the degradation of insulin. It is known that increased insulin levels stimulate ovarian theca cells to secrete enormous amount of androgen (Ehrmann et al. 1995, Allahbadia \& Merchant 2011) and increase LH pulse frequency (Allahbadia \& Merchant 2011), both of these lead to hyperandrogenism. Therefore, hyperinsulinaemia in this study induced the hyperandrogenism, which is the cause of follicular excess as discussed earlier. Further, simultaneously estradiol levels were also higher in stressed rats that developed PCO condition. It is known that a high estradiol concentration in PCO modifies the normal feedback regulation of FSH that results in arrest of maturation of large antral follicles (Franks \& Hardy 2010). Indeed, in this study despite an increase in the number of antral follicles, there was a decrease in the number of active corpora lutea, indicating a reduced rate of ovulation due to failure of some of antral follicles to undergo maturation and ovulation. Thus, this study clearly demonstrates that stress-induced hyperinsulinaemia sets in the sequence of events leading to PCO phenotype in normal cycling rats. To conclude, this study reveals that the ovary responds differentially to the stress depending on the duration of exposure; shorter periods exert suppressive action, whereas a longer exposure results in pathophysiological development resulting in reduced ovulation despite excessive follicular recruitment. Further, the mechanism underlying differential response of the ovary to different stress regimes, despite a similar increase in corticosterone concentration needs to be investigated, focussing on the expression of glucocorticoid receptors and enzymes following different exposure durations.

\section{Declaration of interest}

The authors declare that there is no conflict of interest that could be perceived as prejudicing the impartiality of the research reported.

\section{Funding}

This work was supported by UGC under Special Assistance Programme [F.4-20/2015/CAS-1(SAP-II)] and NON-NET fellowship scheme [DV9/192/NON-NETFS/2013-14, Dated 11/11/2013)].

\section{Acknowledgements}

The authors thank UGC for financial support under SAP and award of fellowship to the first author.

\section{References}

Aebi H 1984 Catalase in vitro methods. Methods in Enzymology 105 121-126. (doi:10.1016/s0076-6879(84)05016-3)

Agarwal A, Gupta S \& Sharma RK 2005 Role of oxidative stress in female reproduction. Reproduction Biology and Endocrinology 14 3-28. (doi:10.1186/1477-7827-3-28)

Allahbadia GN \& Merchant R 2011 Polycystic ovary syndrome and impact on health. Middle East Fertility Society Journal 16 19-37. (doi:10.1016/j. mefs.2010.10.002)

Barham D \& Trinder P 1972 An improved color reagent for the determination of blood glucose by the oxidase system. Analyst $\mathbf{9 7}$ 142-145. (doi:10.1039/an9729700142)

Barra R, Cruz G, Mayerhofer A, Paredes A \& Lara HE 2014 Maternal sympathetic stress impairs follicular development and puberty of the offspring. Reproduction 148 137-145. (doi:10.1530/REP-14-0150)

Borras C, Gambini J, Lopez-Grueso R, Pallardo FV \& Vina J 2010 Direct antioxidant and protective effect of estradiol on isolated mitochondria. Biochimica et Biophysica Acta 1802 205-211. (doi:10.1016/j. bbadis.2009.09.007)

Benzie IF \& Strain JJ 1996 The ferric reducing ability of plasma (FRAP) as a measure of 'antioxidant power': the FRAP assay. Analytical Biochemistry 239 70-76. (doi:10.1006/abio.1996.0292)

Bhat MS \& Yajurvedi HN 2011 Stress induced alterations in pre-pubertal ovarian follicular development in rat. Journal of Stress Physiology and Biochemistry 7 51-68.

Breen KM, Stackpole CA, Clarke IJ, Pytiak AV, Tilbrook AJ, Wagenmaker ER, Young EA \& Karsch FJ 2004 Does the type II glucocorticoid receptor 
mediate cortisol-induced suppression in pituitary responsiveness to gonadotropinreleasing hormone? Endocrinology 145 2739-2746. (doi:10.1210/en.2004-0123)

Campbell KL 1979 Ovarian granulosa cells isolated with EGTA and hypertonic sucrose: cellular integrity and function. Biology of Reproduction 21 773-786. (doi:10.1095/biolreprod21.4.773)

Campbell CS \& Schwartz NB 1980 The impact of constant light on the estrous cycle of the rat. Endocrinology 106 1230-1238. (doi:10.1210/ endo-106-4-1230)

Chrousos GP, Torpy DJ \& Gold PW 1998 Interactions of the hypothalamopituitary-adrenal axis and the female reproductive system: clinical implications. Annals of Internal Medicine 129 229-240. (doi:10.7326/0003-4819-129-3-199808010-00012)

Compton MM 1992 A biochemical hallmark of apoptosis: internucleosomal degradation of the genome. Cancer and Metastasis Review 11 105-119. (doi:10.1007/BF00048058)

Cooper RL, Goldman JM \& Vandenbergh JG 1993 Monitoring of the estrous cycle in the laboratory rodent by vaginal lavage. In Methods in Toxicology: Female Reproductive Toxicology, pp 45-56. Eds JJ Heindel \& RE Chapin. San Diego, CA, USA: Academic Press.

Daley CA, Macfarlane MS, Sakurai H \& Adams TE 1999 Effect of stress-like concentrations of cortisol on follicular development and the preovulatory surge of luteinizing hormone in sheep. Journal of Reproduction and Fertility 117 11-16. (doi:10.1530/jrf.0.1170011)

Das M, Djahanbakhch O, Hacihanefioglu B, Saridogan E, Ikram M, Ghali L, Raveendran M \& Storey A 2008 Granulosa cell survival and proliferation are altered in Polycystic Ovary Syndrome. Journal of Clinical Endocrinology and Metabolism 93 881-887. (doi:10.1210/jc.2007-1650)

de Melo AS, Dias SV, Cavalli Rde C, Cardoso VC, Bettiol H, Barbieri MA, Ferriani RA \& Vieira CS 2015 Pathogenesis of polycystic ovary syndrome: multifactorial assessment from the foetal stage to menopause. Reproduction 150 R11-R24. (doi:10.1530/REP-14-0499)

Devine PJ, Perreault SD \& Ludere U 2012 Roles of reactive oxygen species and antioxidants in ovarian toxicity. Biology of Reproduction 86 1-10. (doi:10.1095/biolreprod.111.095224)

Dorfman M, Arancibia S, Fiedler JL \& Lara HE 2003 Chronic intermittent cold stress activates ovarian sympathetic nerves and modifies ovarian follicular development in the rat. Biology of Reproduction $\mathbf{6 8}$ 2038-2043. (doi:10.1095/biolreprod.102.008318)

Ehrmann DA, Barnes RB \& Rosenfield RL 1995 Polycystic ovary syndrome as a form of functional ovarian hyperandrogenism due to dysregulation of androgen secretion. Endocrine Reviews 6 322-353. (doi:10.1210/ er.16.3.322

Franks S \& Hardy K 2010 Aberrant follicle development and anovulation in polycystic ovarian syndrome. Annales d'Endocrinologie 71 228-230. (doi:10.1016/j.ando.2010.02.007)

Gambineri A, Pelusi C, Vicennati V, Pagotto U \& Pasquali R 2002 Obesity and the polycystic ovary syndrome. International Journal of Obesity and Related Metabolic Disorders 26 883-896. (doi:10.1038/ sj.ijo.0801994)

Gao Y, Chen F, Kong QQ, Ning SF, Yuan HJ, Lian HY, Luo MJ \& Tan JH 2016 Stresses on female mice impair oocyte developmental potential: effects of stress severity and duration on oocytes at the growing follicle stage. Reproductive Sciences 23 1148-1157. (doi:10.1177/1933719116630416)

Greenwald GS \& Roy SJ 1994 Follicular development and its control. In Physiology of Reproduction, Edn 2, pp 629-724. Eds E Knobil \& JD Neil. New York, NY, USA: Raven Press Ltd.

Greiner M, Paredes A, Araya V \& Lara HE 2005 Role of stress and sympathetic innervations in the development of polycystic ovary syndrome. Endocrine 28 319-324. (doi:10.1385/ENDO:28:3:319)

Grissom N, Kerr W \& Bhatnagar S 2008 Struggling behavior during restraint is regulated by stress experience. Behavioural Brain Research 191 219-226. (doi:10.1016/j.bbr.2008.03.030)

Gupta S, Sekhon L, Aziz N \& Agarwal A 2008 The impact of oxidative stress on female reproduction and ART: an evidence-based review. In Infertility and Assisted Reproduction, pp 178-186. Eds A Makrigiannakis, B Rizk, JG Velasco \& H Sallam. New York, NY, USA: Cambridge UP.

Habig WJ, Babst MJ \& Jacoby WJ 1974 Glutathione-S-transferase the 1st enzymatic step in mercapturic acid formation. Journal of Biological Chemistry 249 7130-7139
Hillier SG 1994 Hormonal control of folliculogenesis and luteinizaion. In Molecular Biology of the Female Reproductive System, pp 1-37. Ed JK Findlay. San Diego, USA: Academic Press.

Jeong JY, Lee DH \& Kang SS 2013 Effects of chronic restraint stress on body weight, food intake, and hypothalamic gene expressions in mice. Endocrinology and Metabolism 28 288-296. (doi:10.3803/ EnM.2013.28.4.288)

Kasibhatla S, Amarante-Mendes GP, Finucane D, Brunner T, BossyWetzel E \& Green DR 2006 Acridine orange/ethidium bromide (AO/ EB) staining to detect apoptosis. Cold Spring Harbor Protocols 2006 (pii: pdb.prot4493). (doi:10.1101/pdb.prot4493)

Kyrou I \& Tsigos C 2008 Chronic stress, visceral obesity and gonadal dysfunction. Hormones 7 287-293. (doi:10.14310/horm.2002.1209)

Levy BH \& Tasker JG 2012 Synaptic regulation of the hypothalamicpituitary-adrenal axis and its modulation by glucocorticoids and stress. Frontiers in Cellular Neuroscience 6 1-13. (doi:10.3389/ fncel.2012.00024)

Lian HY, Gao Y, Jiao GZ, Sun MJ, Wu XF, Wang TY, Li H \& Tan JH 2013 Antioxidant supplementation overcomes the deleterious effects of maternal restraint stress-induced oxidative stress on mouse oocytes. Reproduction 146 559-568. (doi:10.1530/REP-13-0268)

Liu J \& Mori A 1999 Stress, aging and oxidative damage. Neurochemical Research 24 1479-1497. (doi:10.1023/A:1022597010078)

Mancini A, Leone E, Festa R, Grande G, Silvestrini A, De Marinis L, Pontecorv A, Maira G, Littarru GP \& Meucci E 2008 Effects of testosterone on antioxidant systems in male secondary hypogonadism. Journal of Andrology 29 622-629. (doi:10.2164/jandrol.107.004838)

Marklund S \& Marklund G 1974 Involvement of the superoxide anion radical in the autoxidation of pyrogallol and a convenient assay for SOD. European Journal of Biochemistry 47 469-473. (doi:10.1111/j.1432-1033.1974.tb03714.x)

Mittal M, Siddiqui MR, Tran K, Reddy SP \& Malik AB 2014 Reactive oxygen species in inflammation and tissue injury. Antioxidants and Redox Signaling 20 1126-1167. (doi:10.1089/ars.2012.5149)

Mourlon V, Naudon L, Giros B, Crumeyrolle-Arias M \& Dauge V 2011 Early stress leads to effects on estrous cycle and differential responses to stress. Physiology and behavior 102 304-310. (doi:10.1016/j. physbeh.2010.11.003)

Murray AA, Gosden RG, Allison V \& Spears N 1998 Effect of androgens on the development of mouse follicles growing in vitro. Journal of Reproduction and Fertility 113 27-33. (doi:10.1530/jrf.0.1130027)

Nayanatara AK, Nagaraja HS \& Anupama BK 2005 The effect of repeated swimming stress on organ weights and lipid peroxidation in rats. Thai Journal of Physiological Sciences 18 3-9.

Nirupama R, Devaki M \& Yajurvedi HN 2010 Repeated acute stress induced alterations in carbohydrate metabolism in rat. Journal of Stress Physiology and Biochemistry 6 44-55.

Ohkawa H, Ohishi N \& Yogi K 1979 Assay for LPO in animal tissue by thiobarbituric acid reaction. Analytical Biochemestry 95 351-358. (doi:10.1016/0003-2697(79)90738-3)

Ozawa M, Tabayashi D, Latief TA, Shimizu T, Oshima I \& Kanai Y 2005 Alterations in follicular dynamics and steroidogenic abilities induced by heat stress during follicular recruitment in goats. Reproduction 129 621-630. (doi:10.1530/rep.1.00456)

Paredes A, Galvez A, Leyton V, Aravena G, Fiedler JL, Bustamante D \& Lara HE 1998 Stress promotes development of ovarian cysts in rats. Endocrine 8 309-315. (doi:10.1385/ENDO:8:3:309)

Patel S, Zhou C, Rattan S \& Flaws JA 2015 Effects of endocrine-disrupting chemicals on the ovary. Biology of Reproduction 93 1-9. (doi:10.1095/ biolreprod.115.130336)

Pedersen T \& Peters H 1968 Proposal for a classification of oocytes and follicles in the mouse ovary. Journal of Reproduction and Fertility 17 555-557. (doi:10.1530/jrf.0.0170555)

Roth Z, Meidan R, Braw-Tal R \& Wolfenson D 2000 Immediate and delayed effects of heat stress on follicular development and its association with plasma follicule stimulating hormone and inhibin concentration in cows. Journal of Reproduction and Fertility 120 83-90. (doi:10.1530/ reprod/120.1.83)

Ruder EH, Hartman TJ \& Goldman MB 2009 Impact of oxidative stress on female fertility. Current Opinion in Obstetrics Gynecology 21 219-222. (doi:10.1097/GCO.0b013e32832924ba) 
Said RS, Nada AS \& El-Demerdash E 2012 Sodium selenite improves folliculogenesis in radiation-induced ovarian failure: a mechanistic approach. PLOS ONE 7 e50928. (doi:10.1371/journal.pone.0050928)

Saraswathi CD, Gupta SK \& Sreemantula S 2012 Protective effect of Symplocos racemosa bark on cold restraint stress induced reproductive changes in female rats. Journal of Natural Products 5 251-258.

Saraswathi CD, Sreemantula S \& Prakash WS 2010 Effect of chronic cold restraint and immobilization stress on estrous cycle in rats. Pharmacology Online 2 151-160. (doi:10.3389/fnins.2014.00456)

Sen A, Prizant H, Light A, Biswas A, Hayes E, Lee HJ, Barad D, Gleicher N \& Hammes SR 2014 Androgens regulate ovarian follicular development by increasing follicle stimulating hormone receptor and microRNA $-125 b$ expression. PNAS 111 3008-3013. (doi:10.1073/pnas.1318978111)

Shivanandappa T \& Venkatesh S 1997 A colorimetric assay method for 3beta-hydroxy delta-5-steroid dehydrogenase. Analytical Biochemistry 254 57-61. (doi:10.1006/abio.1997.2406)

Sinha k, Das J, Pal PB \& Sil PC 2013 Oxidative stress: the mitochondriadependent and mitochondria-independent pathways of apoptosis. Archives of Toxicology 87 1157-1180. (doi:10.1007/s00204-013-1034-4)

Spiers JG, Chen HC, Sernia C \& Lavidis NA 2015 Activation of the hypothalamic-pituitary-adrenal stress axis induces cellular oxidative stress. Frontiers in Neuroscience 8 456. (doi:10.3389/fnins.2014.00456)

Tappel AL 1978 GPx and hydroperoxidase. Methods in Enzymology 52 506-513.

Tomas E, Lin YS, Dagher Z, Saha A, Luo Z, Ido Y \& Ruderman NB 2002 Hyperglycemia and insulin resistance: possible mechanisms. Annals of the New York Academy of Sciences 967 43-51. (doi:10.1111/j.1749-6632.2002.tb04262.x)

Vendola KA, Zhou J, Wang J \& Bondy CA 1999 Androgens promote the IGF-I and IGF-I receptor gene expression in the primate ovary. Human Reproduction 14 2328-2332. (doi:10.1093/humrep/14.9.2328)

Weil S, Vendola K, Zhou J \& Bondy CA 1999 Androgen and follicle stimulating hormone interactions in primate ovarian follicle development. Journal of Clinical Endocrinology and Metabolism 84 2951-2956. (doi:10.1210/jcem.84.8.5929)

Whirledge S \& Cidlowski JA 2010 Glucocorticoid, stress, and fertility. Minerva Endocrinologica 35 109-125.

Wu LM, Liu YS, Tong XH, Shen N, Jin RT, Han $\mathrm{H}$, Hu MH, Wang W \& Zhou GX 2011 Inhibition of follicular development induced by chronic unpredictable stress is associated with growth and differentiation factor 9 and gonadotropin in mice. Biology of Reproduction 86 1-7. (doi:10.1095/biolreprod.111.093468)

Yoshida M, Sanbuissyo A, Hisada S, Takahashi M, Ohno Y \& Nishikawa A 2009 Morphological characterization of ovary under normal cycling in rats and its viewpoints of ovarian toxicity detection. Journal of Toxicologyical Sciences 34 SP189-SP197. (doi:10.2131/jts.34.s189)

Yuan HJ, Han X, He N, Wang GL, Gong S, Lin J, Gao M \& Tan JH 2016 Glucocorticoids impair oocyte developmental potential by triggering apoptosis of ovarian cells via activating the Fas system. Scientific Reports 6 24036. (doi:10.1038/srep24036)

Zardooz H, AsI SZ, Veservi MKG \& Hedayati M 2006 Effect of chronic restraint stress on carbohydrate metabolism in rat. Physiology and Behavior 89 373-378. (doi:10.1016/j.physbeh.2006.06.023)

Zhang SY, Wang JZ, Li JJ, Wei DL, Sui HS, Zhang ZH, Zhou P \& Tan JH 2011 Maternal restraint stress diminishes the developmental potential of oocytes. Biology of Reproduction 84 672-681. (doi:10.1095/ biolreprod.110.087890)

Received 25 July 2016

First decision 3 August 2016

Revised manuscript received 19 September 2016

Accepted 20 September 2016 